\title{
Long-acting muscarinic antagonists: a potential add-on therapy in the treatment of asthma?
}

\author{
William W. Busse ${ }^{1}$, Ronald Dahl' ${ }^{2}$ Christine Jenkins $^{3}$ and Alvaro A. Cruz ${ }^{4}$
}

Affiliations: ${ }^{1}$ University of Wisconsin School of Medicine and Public Health, Madison, WI, USA. ${ }^{2}$ Allergy Centre, Odense University Hospital, Odense, Denmark. ${ }^{3}$ The George Institute for Global Health, Sydney, Australia. ${ }^{4}$ ProAR - Universidade Federal da Bahia, Bahia, Brazil.

Correspondence: William W. Busse, University of Wisconsin, K4/910, 9988 Clinical Science Center, 600 Highland Avenue, Madison, WI 53792, USA. E-mail: wwbamedicine.wisc.edu

ABSTRACT Asthma is a chronic inflammatory disorder of the airways that is a major global burden on both individuals and healthcare systems. Despite guideline-directed treatment, a significant proportion of patients with asthma do not achieve control. This review focuses on the potential use of long-acting anticholinergics as bronchodilators in the treatment of asthma, with results published from clinical trials of glycopyrrolate, umeclidinium and tiotropium. The tiotropium clinical trial programme is the most advanced, with data available from a number of phase II and III studies of tiotropium as an add-on to inhaled corticosteroid maintenance therapy, with or without a long-acting $\beta_{2}$-agonist, in patients across asthma severities. Recent studies using the Respimat Soft Mist inhaler have identified $5 \mu \mathrm{g}$ once daily as the preferred dosing regimen, which has shown promising results in adults, adolescents and children with asthma. Tiotropium Respimat has recently been incorporated into the Global Initiative for Asthma 2015 treatment strategy as a recommended alternative therapy at steps 4 and 5 in adult patients with a history of exacerbations. The increasing availability of evidence from ongoing and future clinical trials will be beneficial in determining where long-acting anticholinergic agents fit in future treatment guidelines across a variety of patient populations and disease severities.

0 @ERSpublications

Anticholinergics as an add-on to current treatment options may address the current unmet need in asthma management http://ow.ly/TTile

\section{Introduction: the unmet need in asthma management}

Asthma is a multifactorial inflammatory disorder of the airways that affects approximately 235 million people worldwide [1], with estimates that 400 million people will be affected by 2025 [2]. Currently, asthma is reported to be the most common chronic disease in children [2], and in the USA, $10 \%$ of children aged 12-18 years have asthma [3].

The preferred treatment strategy proposed by the Global Initiative for Asthma (GINA) recommends initial treatment with inhaled corticosteroids (ICS) followed by increasing the ICS dose or adding on a long-acting $\beta_{2}$-agonist (LABA) to achieve control. In patients with more severe disease, referral for specialist investigation and consideration of add-on therapeutic alternatives is recommended if control is not achieved, provided poor adherence, inadequate inhaler technique, persistent exposure and comorbidities have been addressed [4]. Despite treatment according to guidelines, a significant proportion of asthma patients have disease that remains inadequately controlled [5-9]. The Asthma Insights and

Received: June 232015 | Accepted after revision: Aug 102015

Conflict of interest: Disclosures can be found alongside the online version of this article at err.ersjournals.com

Provenance: Publication of this peer-reviewed article was supported by Boehringer Ingelheim Pharma GmbH and Co. KG, Ingelheim am Rhein, Germany (article sponsor, European Respiratory Review issue 139).

Copyright CERS 2016. ERR articles are open access and distributed under the terms of the Creative Commons Attribution Non-Commercial Licence 4.0. 
Reality study and The Reality of Asthma Control study indicate that up to $49 \%$ and $53 \%$, respectively, of adults receiving treatment have inadequately controlled asthma [10, 11], and up to $64 \%$ of adolescent patients have asthma that is inadequately controlled by currently available therapies [12]. Because a significant proportion of patients have poorly controlled symptomatic asthma despite treatment according to current guidelines, it is important to appreciate the impact this has on patients' lifestyles as well as on healthcare resources and costs.

\section{The impact of poorly controlled asthma}

Poorly controlled asthma places a burden on both patients and society. Worldwide, inadequately controlled asthma results in almost 14 million years of life lived annually in less than ideal health (lived with disability) [13]. Studies have shown that poorly controlled asthma also places a burden on healthcare systems and family finances [14]. For example, in the USA in 2007, there were 1.4 million asthma-related hospital outpatient department visits ( 0.6 million for adult patients and 0.8 million for paediatric patients) and 1.75 million asthma-related emergency department visits $(1.11$ million for adult patients and 0.64 million for paediatric patients) [15]. In addition, healthcare costs are greater with increasing asthma severity. Even higher total and asthma-related healthcare costs are attributed to asthma exacerbations [16], which can occur in any asthma patient, are potentially life-threatening and may affect the disease course $[17,18]$. While only an estimated $20 \%$ of asthma patients experience exacerbations that require emergency treatment or hospitalisation, these events account for over $80 \%$ of the total direct costs associated with asthma [19]. Hence, there is an ongoing need to maintain and improve the management of asthma. In addition, the overlap between asthma and chronic obstructive pulmonary disease (COPD) has been increasingly recognised [4], with patients who demonstrate concomitant features of both diseases experiencing more frequent exacerbations $[20,21]$ and, therefore, requiring particular attention in order to optimise treatment.

\section{Achieving asthma control}

To manage asthma effectively and determine the need for additional treatment, it is important for physicians to ascertain the level of patients' disease control [22], which involves the assessment of both symptom control and future risk of adverse outcomes [4]. Determination of the level of asthma control also includes rescue medication use and level of activity limitation [4]. Validated assessment scales, including the Asthma Control Questionnaire (ACQ) [23], the Asthma Control Test (QualityMetric Incorporated, Lincoln, RI, USA) and the Asthma Quality of Life Questionnaire [24], can be used to identify patients with poorly controlled asthma and to track patient progress. Adverse outcomes include: future risk of exacerbations, which may be predicted and possibly affected by previous incidence of exacerbations; persistent airflow limitation; poor inhaler technique; nonadherence to treatment regimens; medication side-effects; and factors such as concurrent smoking [4, 25].

Considering the high proportion of patients with asthma who do not achieve control despite guideline-directed care, new treatment options are required to address the current unmet need in asthma management. The long-acting anticholinergic bronchodilator tiotropium bromide has recently been incorporated into the revised GINA 2015 strategy as an alternative add-on therapy at steps 4 and 5 in adult patients with a history of exacerbations [4], indicating that long-acting anticholinergics provide an important treatment option.

\section{Anticholinergics in the treatment of asthma}

There has been a recent focus on the role of the neurotransmitter acetylcholine in the pathophysiology of asthma. The release of acetylcholine from parasympathetic nerves increases airway tone, contracts bronchial smooth muscle, and leads to mucus secretion and vasodilation, primarily via interaction with M3 muscarinic receptors, which are located in the human lung and on the airway ganglia, nerves, smooth muscle, mucous glands and pulmonary vascular endothelium [26-29]. Inflammation of the airways also has an important pathophysiological role in asthma, and acetylcholine induces the release of pro-inflammatory mediators from bronchial epithelial cells and cells of the immune system, including macrophages, mast cells, monocytes, granulocytes, neutrophils and eosinophils [27, 30-32].

Muscarinic antagonists compete with acetylcholine at the muscarinic receptors on airway smooth muscle to induce bronchodilation [28], and have also been postulated to have anti-inflammatory actions by inhibiting the release of pro-inflammatory cytokines from epithelial and immune cells [30, 31]. Given these actions, there is a mechanistic rationale for the use of muscarinic antagonists in the treatment of poorly controlled asthma. 


\section{Short-acting anticholinergics}

The short-acting anticholinergic agents ipratropium bromide and oxitropium bromide have been used in the treatment of asthma for several years, although they are considered to be less effective than short-acting $\beta_{2}$-agonists (SABAs) in achieving acute bronchodilation, which, together with their short duration of action, limits their use as controllers in the treatment of asthma [28, 33-35]. However, there are data to suggest that treatment with short-acting anticholinergic and SABA combination therapy may provide a more effective option than treatment with SABAs alone, particularly in the acute setting [36-41].

\section{Long-acting anticholinergics}

Acknowledging the weaknesses of short-acting agents, there has been increasing interest in the use of longer-acting anticholinergic bronchodilators as controller medications in the treatment of asthma. Their prolonged duration of action relative to SABAs may provide an additional option in the treatment of asthma as an add-on to ICS alone or ICS plus LABA maintenance therapy. A number of publications related to randomised clinical trials of the long-acting anticholinergic agents glycopyrronium bromide, umeclidinium bromide and tiotropium bromide in patients with asthma were identified from recent literature, with ongoing trials listed on www.ClinicalTrials.gov.

Glycopyrrolate is an approved bronchodilator for the treatment of COPD in a number of countries worldwide, including in the European Union. In a small crossover study in 10 patients to test the potential utility of glycopyrrolate (delivered via the DeVilbiss nebuliser; DeVilbiss Healthcare, Somerset, PA, USA) in the treatment of asthma, glycopyrrolate was found to significantly prolong bronchodilation and bronchoprotection compared with both ipratropium and placebo [42]. Patient recruitment is currently ongoing for a phase II crossover study of glycopyrrolate add-on therapy in adult patients with mild or moderate asthma (www.ClinicalTrials.gov identifier NCT02296411), which will help to determine whether glycopyrrolate may provide an additional option for the treatment of asthma.

Umeclidinium is an approved maintenance bronchodilator for the treatment of COPD as both monotherapy and in combination with the LABA vilanterol. Recent phase II clinical trials have assessed the efficacy of umeclidinium as monotherapy and in combination therapy with ICS in adult patients with asthma. A double-blind crossover study of umeclidinium monotherapy in 350 patients with asthma found no conclusive therapeutic benefit following treatment with this medication in patients not receiving ICS (improvement in trough forced expiratory volume in $1 \mathrm{~s}$ (FEV1) compared with placebo: 11-88 $\mathrm{mL}$ ), with no dose-ordered response or evidence of twice-daily dosing providing additional benefit over once-daily dosing [43]. However, the results of a double-blind crossover study in 421 patients with asthma suggest that ICS plus umeclidinium combination therapy provides a potential treatment option. Across all treatment periods, improvements in trough FEV1 (compared with ICS: $26-55 \mathrm{~mL}$ ) and improvements in morning peak expiratory flow (PEF) (compared with ICS: 15.9-22.9 L· $\mathrm{min}^{-1}$ ) and evening PEF (compared with ICS: 16.2-28.8 L. $\mathrm{min}^{-1}$ ) were observed following combination therapy. Post hoc analyses demonstrated that the effects of ICS plus umeclidinium were greatest in patients with fixed airflow obstruction [44]. Following these promising initial results, future, long-term studies of umeclidinium combination therapy in the treatment of asthma with longer washout periods or alternative study design would be beneficial.

Tiotropium has been indicated for the treatment of COPD for over 10 years and has recently been approved for use in the treatment of asthma in adults in a number of countries worldwide, including the European Union, Japan and the USA, and is currently undergoing regulatory review in a number of countries. Tiotropium is recommended as an alternative add-on treatment option at GINA steps 4 and 5 in adult patients with a history of exacerbations [4]. Of the clinical trial programmes in long-acting anticholinergics, the tiotropium programme is currently the most advanced, with results published from a number of phase II and III studies of tiotropium as an add-on to ICS maintenance therapy, with or without a LABA, in patients across severities of asthma.

\section{Tiotropium in the treatment of asthma}

We present an overview of currently available data for tiotropium in asthma following a PubMed search (April 2015) using the search terms "tiotropium" and "asthma" with no date restrictions. This search was limited to clinical trials in humans with results published in English.

The first double-blind, placebo-controlled, crossover study in 12 male patients with mild atopic asthma evaluated single doses of tiotropium $(10,40$ or $80 \mu \mathrm{g})$ from a dry-powder inhaler (Boehringer Ingelheim, Ingelheim am Rhein, Germany) and found mild bronchodilation and significant protection against methacholine challenge, which were maintained for up to $24 \mathrm{~h}$ [45]. Later studies were then performed using the Spiriva HandiHaler device (Boehringer Ingelheim Pharmaceuticals, Inc., Ridgefield, CT, USA), with more recent trials assessing the efficacy and safety of tiotropium delivered via the Respimat Soft Mist inhaler (Boehringer Ingelheim). 
Tiotropium add-on therapy delivered via the Spiriva HandiHaler device in adult patients Early proof-of-concept studies of tiotropium in asthma, delivered via the Spiriva HandiHaler device, indicated that tiotropium provides sustained bronchodilation and protection against bronchoconstriction induced by methacholine challenge. In a study of 10 asthmatic patients with mild or moderate airway hyperresponsiveness, tiotropium $18 \mu \mathrm{g}$ provided significant protection against methacholine challenge $30 \mathrm{~min}$ after inhalation [46]. Once-daily tiotropium $18 \mu \mathrm{g}$, as an add-on to salmeterol therapy and combined with halving the ICS dose, provided significant improvements in lung function in a 4-week study of 26 patients with severe asthma; however, no significant change in mini-Asthma Quality of Life Questionnaire scores was observed [47]. When compared with oxitropium in a study of 44 patients with asthma, tiotropium $18 \mu \mathrm{g}$ provided greater protection against methacholine-induced bronchoconstriction $60 \mathrm{~min}$ after inhalation [48].

Further studies of tiotropium delivered via the Spiriva HandiHaler device were subsequently performed in selected patient populations. A study of 17 Japanese patients with severe persistent asthma demonstrated that tiotropium add-on to high-dose ICS, with or without a LABA, resulted in significant improvements in FEV1 ( $p=0.001$ ), which correlated with sputum neutrophil levels and inversely correlated with sputum eosinophil levels [49]. In a study of once-daily tiotropium $18 \mu \mathrm{g}$ add-on to high-dose ICS plus a LABA over 12 weeks in 138 Korean patients with severe persistent asthma, 30\% of patients responded to tiotropium therapy (an increase in FEV 1 of $\geqslant 15 \%$ or $\geqslant 200 \mathrm{~mL}$ for $\geqslant 8$ consecutive weeks) and pharmacogenetic analyses demonstrated that the presence of the Arg16Gly polymorphism at ADRB2 may predict response to tiotropium [50].

The first well-powered clinical trial in a larger patient cohort was the Tiotropium Bromide as an Alternative to Increased Inhaled Corticosteroid in Patients Inadequately Controlled on a Lower Dose of Inhaled Corticosteroid (TALC) study (NCT00565266), which compared the efficacy of tiotropium $18 \mu \mathrm{g}$ delivered via the Spiriva HandiHaler device as an add-on to ICS with doubling the dose of ICS (twice-daily beclomethasone $160 \mu \mathrm{g}$ ) and with twice-daily salmeterol $50 \mu \mathrm{g}$ as an add-on to ICS in 210 patients with symptomatic asthma. Data showed that when added to ICS therapy, tiotropium improved lung function and symptom control compared with doubling the ICS dose (mean difference between tiotropium and doubling the ICS dose in morning PEF: $25.8 \mathrm{~L} \cdot \mathrm{min}^{-1}, \mathrm{p}<0.001$; evening PEF: $35.3 \mathrm{~L} \cdot \mathrm{min}^{-1}$, $\mathrm{p}<0.001$; pre-bronchodilator FEV1: $100 \mathrm{~mL}, \mathrm{p}=0.004$; seven-question ACQ (ACQ-7): -0.18, $\mathrm{p}=0.02$ ), and was noninferior to salmeterol [51]. A follow-up analysis of the TALC study data indicated that improved lung function, in terms of both FEV1 and morning PEF, following treatment with tiotropium was particularly apparent in patients with higher cholinergic tone, identified by a lower resting heart rate, and increased airway obstruction, which may help to inform future treatment decisions [52].

\section{Tiotropium add-on therapy delivered via the Respimat Soft Mist inhaler in adult patients}

The TIOSPIR (Tiotropium Safety and Performance in Respimat) trial (NCT01126437) in 17135 patients with COPD confirmed that the safety profiles of tiotropium $5 \mu \mathrm{g}$ and $2.5 \mu \mathrm{g}$ delivered via the Respimat inhaler (hereinafter referred to as tiotropium Respimat) were comparable with those of tiotropium $18 \mu \mathrm{g}$ delivered via the Spiriva HandiHaler device [53]. A number of studies have now evaluated the efficacy of tiotropium Respimat compared with placebo, each as an add-on to usual care with at least ICS in patients with symptomatic asthma. An overview of published clinical trials of tiotropium Respimat in patients with asthma, and the associated key lung function results, is provided in table 1; the incidence of adverse events, serious adverse events and drug-related adverse events, which was comparable between treatment regimens within each trial, is presented in table 2. No deaths were reported in any asthma study.

Two companion proof-of-concept studies examined the role of tiotropium add-on therapy in patients with moderate or severe asthma. KERSTJENS et al. [54] compared the efficacy and safety of once-daily tiotropium $10 \mu \mathrm{g}$ and $5 \mu \mathrm{g}$ with placebo, each as an add-on to at least high-dose ICS plus a LABA (NCT00365560), in 107 patients with severe symptomatic asthma. Tiotropium significantly improved all measures of FEV 1 (table 1) and forced vital capacity compared with placebo. These improvements were sustained over $24 \mathrm{~h}$, with improvements also observed in PEF (table 1), mini-Asthma Quality of Life Questionnaire scores and rescue medication use. Subgroup analyses demonstrated that the effects of tiotropium add-on therapy were independent of sex, FEV1 per cent predicted or reversibility at screening, smoking status, or asthma duration. The incidence of adverse events was comparable between treatment groups (table 2), although dry mouth occurred at a higher incidence in patients treated with tiotropium $10 \mu \mathrm{g}$ [54]. A noninferiority study of B16-Arg/Arg patients with moderate symptomatic asthma (NCT00350207), in whom the efficacy and safety of LABAs have been questioned, found that once-daily tiotropium $5 \mu \mathrm{g}$ was more efficacious than placebo in maintaining improved lung function as an add-on to ICS therapy (table 1). Tiotropium $5 \mu \mathrm{g}$ was also found to be as efficacious as twice-daily salmeterol $50 \mu \mathrm{g}$; the B16-Arg/Arg phenotype has been shown to have no influence on responses to salmeterol add-on therapy in asthmatic patients. There was a slight numerical decrease in rescue medication use (compared with placebo: -0.368 puffs per day over $24 \mathrm{~h}, \mathrm{p}=0.146$ ) and a slight numerical increase in the number of asthma symptom-free days 
TABLE 1 Overview of clinical trials of tiotropium Respimat in adult patients with symptomatic asthma

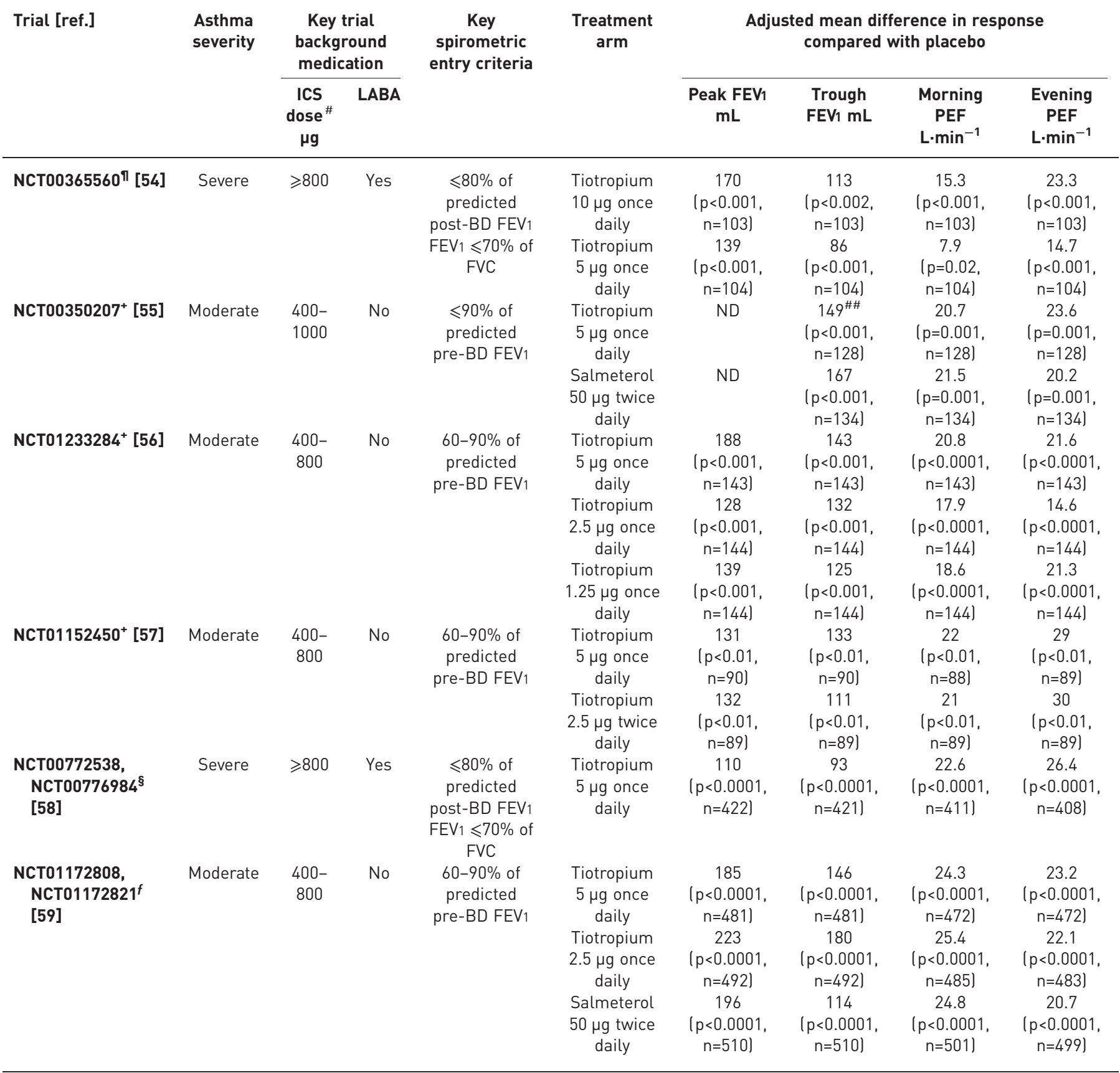

All analyses performed on the full analysis set. ICS: inhaled corticosteroids; LABA: long-acting $\beta_{2}$-agonist; FEV1: forced expiratory volume in 1 s; FVC: forced vital capacity; PEF: peak expiratory flow; BD: bronchodilator (salbutamol); ND: not defined. \#: budesonide or equivalent; ${ }^{\Uparrow}$ : phase II study in adults with severe asthma; ${ }^{+}$: phase II study in adults with moderate asthma; ${ }^{\S}$ : phase III study in adults with severe asthma; ${ }^{f}$ : phase III study in adults with moderate asthma; ${ }^{\# \#}$ : defined as morning pre-dose FEV1.

(compared with placebo: 0.108 days, $\mathrm{p}=0.639$ ) with tiotropium. Furthermore, the frequency of adverse events was similar across treatment groups, although the incidence of nasopharyngitis was higher in the placebo group [55].

The optimal tiotropium treatment regimen for patients with asthma was examined in two phase II studies. The first of these studies, a dose-ranging, crossover study of once-daily tiotropium $5,2.5$ and $1.25 \mu \mathrm{g}$ as an add-on to medium-dose ICS in 149 adults with moderate asthma (NCT01233284), identified $5 \mu \mathrm{g}$ as the optimum therapeutic dose. A statistically significant improvement in most measures of lung function was 
TABLE 2 Overview of adverse events from clinical trials of tiotropium Respimat in patients with symptomatic asthma

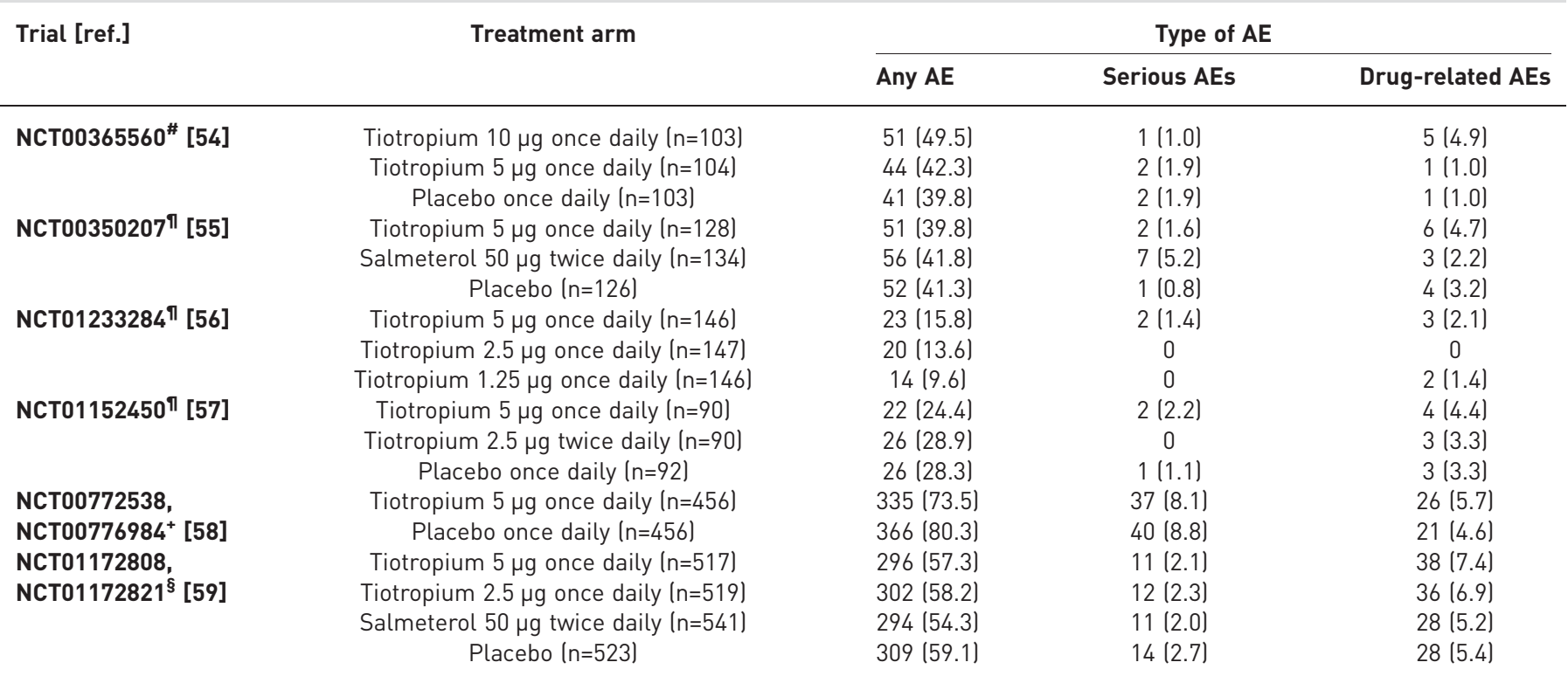

Data are presented as $\mathrm{n}(\%)$. All analyses performed on the treated set. AE: adverse event. ${ }^{\#}$ : phase II study in adults with severe asthma; ${ }^{\text {: }}$ phase II study in adults with moderate asthma; ${ }^{+}$: phase III study in adults with severe asthma; ${ }^{\S}$ : phase III study in adults with moderate asthma.

observed following tiotropium add-on therapy compared with placebo (table 1), with the 5- $\mu$ g dose being consistently associated with the largest improvements. Statistically significant improvements in ACQ-7 scores were also observed (compared with placebo: $5 \mu \mathrm{g},-0.235(\mathrm{p}<0.0001) ; 2.5 \mu \mathrm{g},-0.158(\mathrm{p}=0.0043)$; $1.25 \mu \mathrm{g},-0.190(\mathrm{p}=0.0006)$ ), and adverse events were comparable between treatment groups (table 2) [56]. The second study was a crossover, dose-determination study in 182 adults with moderate asthma (NCT01152450), which confirmed once-daily $5 \mu \mathrm{g}$ as an appropriate dosing regimen. Both once-daily $5 \mu \mathrm{g}$ and twice-daily $2.5 \mu \mathrm{g}$ provided significant and comparable 24 -h bronchodilation (compared with placebo: once-daily $5 \mu \mathrm{g}, 158 \mathrm{~mL}$; twice-daily $2.5 \mu \mathrm{g}, 149 \mathrm{~mL}$ (both $\mathrm{p}<0.01$ )), with improvements in peak FEV1, trough FEV1, and morning and evening PEF that were also statistically significant with both dosing regimens (table 1). Tiotropium add-on therapy significantly improved mean ACQ-7 score (compared with placebo: once-daily $5 \mu \mathrm{g},-0.274(\mathrm{p}<0.01)$; twice-daily $2.5 \mu \mathrm{g},-0.190(\mathrm{p}<0.01))$ and adverse events were comparable between all treatment regimens (table 2) [57].

Subsequent phase III, randomised, double-blind, placebo-controlled, parallel-group trials of once-daily tiotropium add-on to at least ICS maintenance therapy have been performed in adult patients across all severities of symptomatic asthma. In two replicate trials (NCT00772538 and NCT00776984), 912 patients with severe symptomatic asthma received tiotropium $5 \mu \mathrm{g}$ or placebo as an add-on to high-dose ICS plus a LABA over 48 weeks. Tiotropium significantly improved lung function (table 1 and figure 1), and increased the time to both the first severe asthma exacerbation (hazard ratio $0.79, \mathrm{p}=0.03$ ) and the first episode of asthma worsening (hazard ratio $0.69, \mathrm{p}<0.001$ ). Improvements in asthma control and quality of life were also observed, and the incidence of adverse events (table 2) was comparable between treatment groups, with only allergic rhinitis occurring significantly more frequently in the tiotropium treatment group; asthma events and insomnia were significantly more common in the placebo group [58]. Results from two replicate, double-dummy trials in 2103 patients with moderate symptomatic asthma despite treatment with medium-dose ICS (NCT01172808 and NCT01172821) have recently been published. Patients received once-daily tiotropium 5 or $2.5 \mu \mathrm{g}$, twice-daily salmeterol $50 \mu \mathrm{g}$ (delivered via a hydrofluoroalkane metered-dose inhaler), or matching placebo for 24 weeks. Tiotropium provided significant improvements in lung function (table 1 and figure 2) compared with placebo, with the improvements in peak FEV1 maintained over $24 \mathrm{~h}$ in a subset of patients who underwent additional spirometric assessment. Significant improvements in asthma control were observed, as assessed by ACQ-7 responder rate $(5 \mu \mathrm{g}$ : OR $1.32, \mathrm{p}=0.035 ; 2.5 \mu \mathrm{g}$ : $\mathrm{OR} 1.33, \mathrm{p}=0.031)$, with a reduced risk of first severe asthma exacerbation or first episode of asthma worsening following tiotropium add-on therapy. Patterns of response with both tiotropium doses were similar to those seen with salmeterol, and the incidence of adverse events was comparable between all treatment groups (table 2) [59]. 

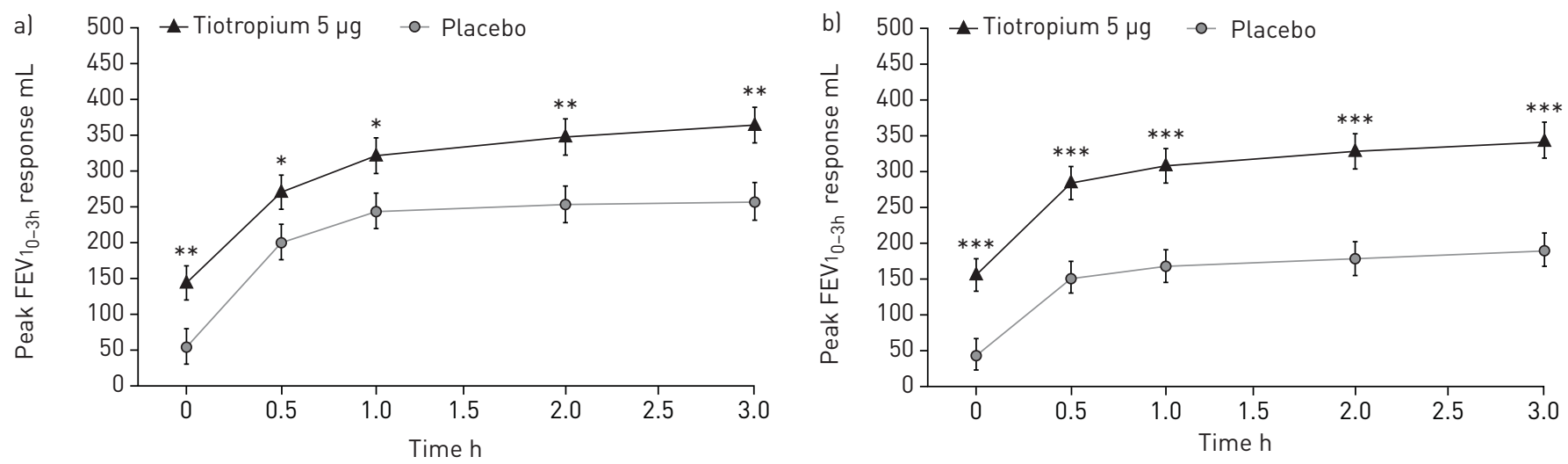

c)

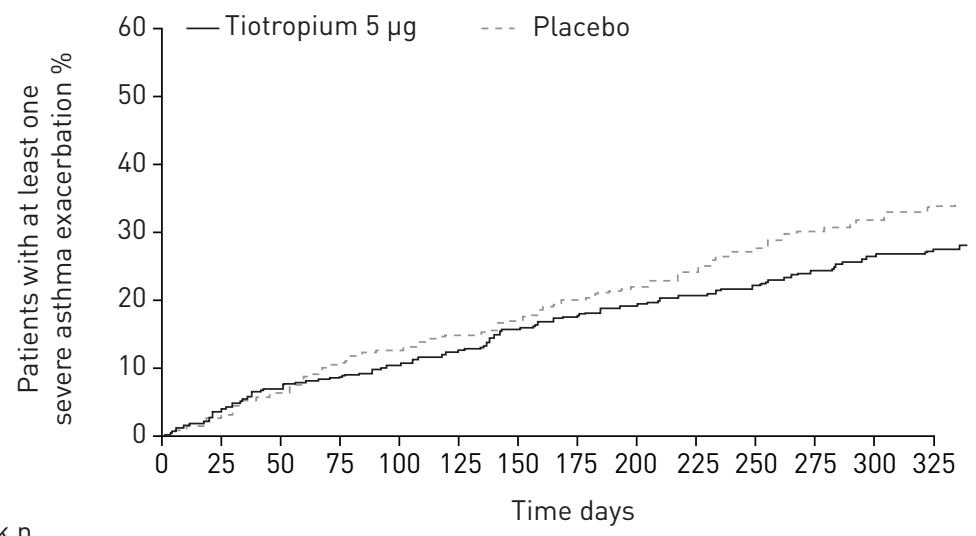

At risk $n$

Placebo

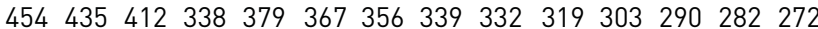

Tiotropium $5 \mu \mathrm{g} 453430409401389378363353 \quad 348339331319308298$

FIGURE 1 Adjusted mean \pm SE response in peak forced expiratory volume in $1 \mathrm{~s}$ within $3 \mathrm{~h}$ post-dosing (peak $\left.F E V_{0-3 \mathrm{~h}}\right)$ at week 24 , following once-daily tiotropium Respimat add-on to high-dose inhaled corticosteroids (ICS) plus a long-acting $\beta_{2}$-agonist (LABA) in adults with severe symptomatic asthma, in a) NCT00772538 and b) NCT00776984. Adjusted for treatment, centre, visit, baseline, treatment-by-visit interaction and baseline-by-visit interaction. Full analysis set. c) Cumulative number of severe exacerbations, over 48 weeks, following once-daily tiotropium Respimat add-on to high-dose ICS plus a LABA in adults with severe symptomatic asthma. Pooled data (NCT00772538 and NCT00776984). Risk reduction of $21 \%$ (hazard ratio $0.79, p=0.03$ ). Full analysis set. ${ }^{*}: p<0.05 ;{ }^{* *}: p<0.01 ;{ }^{* * *}: p<0.001$. Reproduced and modified from [58] with permission from the publisher.

Tiotropium add-on therapy delivered via the Respimat Soft Mist inhaler in paediatric patients

The results of the first studies of tiotropium add-on therapy in paediatric patients with moderate asthma are now available. In the first phase II, randomised, double-blind, incomplete crossover study in 105 adolescent patients aged 12-17 years with moderate symptomatic asthma, patients received once-daily tiotropium 5, 2.5 or $1.25 \mu \mathrm{g}$, or placebo, each as an add-on to medium-dose ICS, with or without a leukotriene modifier (NCT01122680). Once-daily tiotropium add-on therapy improved lung function, compared with placebo, with the 5- $\mu$ g dose providing the greatest improvements at most end-points, including peak FEV1 (compared with placebo: $113 \mathrm{~mL}, \mathrm{p}=0.004$ ), trough FEV1 (compared with placebo: $151 \mathrm{~mL}, \mathrm{p}<0.0001$ ), morning PEF (compared with placebo: $13.2 \mathrm{~L} \cdot \mathrm{min}^{-1}, \mathrm{p}<0.05$ ) and evening PEF (compared with placebo: $17.1 \mathrm{~L} \cdot \mathrm{min}^{-1}, \mathrm{p}=0.0031$ ). Exploratory analyses of adjusted mean ACQ-7 score demonstrated similar improvements in asthma control in all treatment groups. There was a slightly higher rate of adverse events in the tiotropium $5 \mu$ g group (22.5\%), compared with $13.3 \%, 17.3 \%$ and $13.3 \%$ in the tiotropium $2.5 \mu \mathrm{g}$, tiotropium $1.25 \mu \mathrm{g}$ and placebo treatment groups, respectively, due to a marginally increased number of patients with asthma, rhinitis, sinusitis and gastroenteritis [60]. A second phase II study with an identical study design was performed in 101 children aged 6-11 years with moderate symptomatic asthma. Statistically significant improvements in all measures of FEV 1 and forced expiratory flow between $25 \%$ and $75 \%$ of forced vital capacity were observed with all tiotropium doses. Improvements in morning PEF were also significant with all doses, while improvements in evening PEF was significant with the $5-\mu \mathrm{g}$ dose only $\left(17 \mathrm{~L} \cdot \mathrm{min}^{-1}, \mathrm{p}=0.0024\right)$. Trends for improvement in both asthma control and quality of life were observed following tiotropium add-on therapy, although these were not significant. The incidence of adverse events was comparable across all treatment groups [61]. Further phase II and III studies of tiotropium are ongoing in both adolescents and children with varying severities of symptomatic 

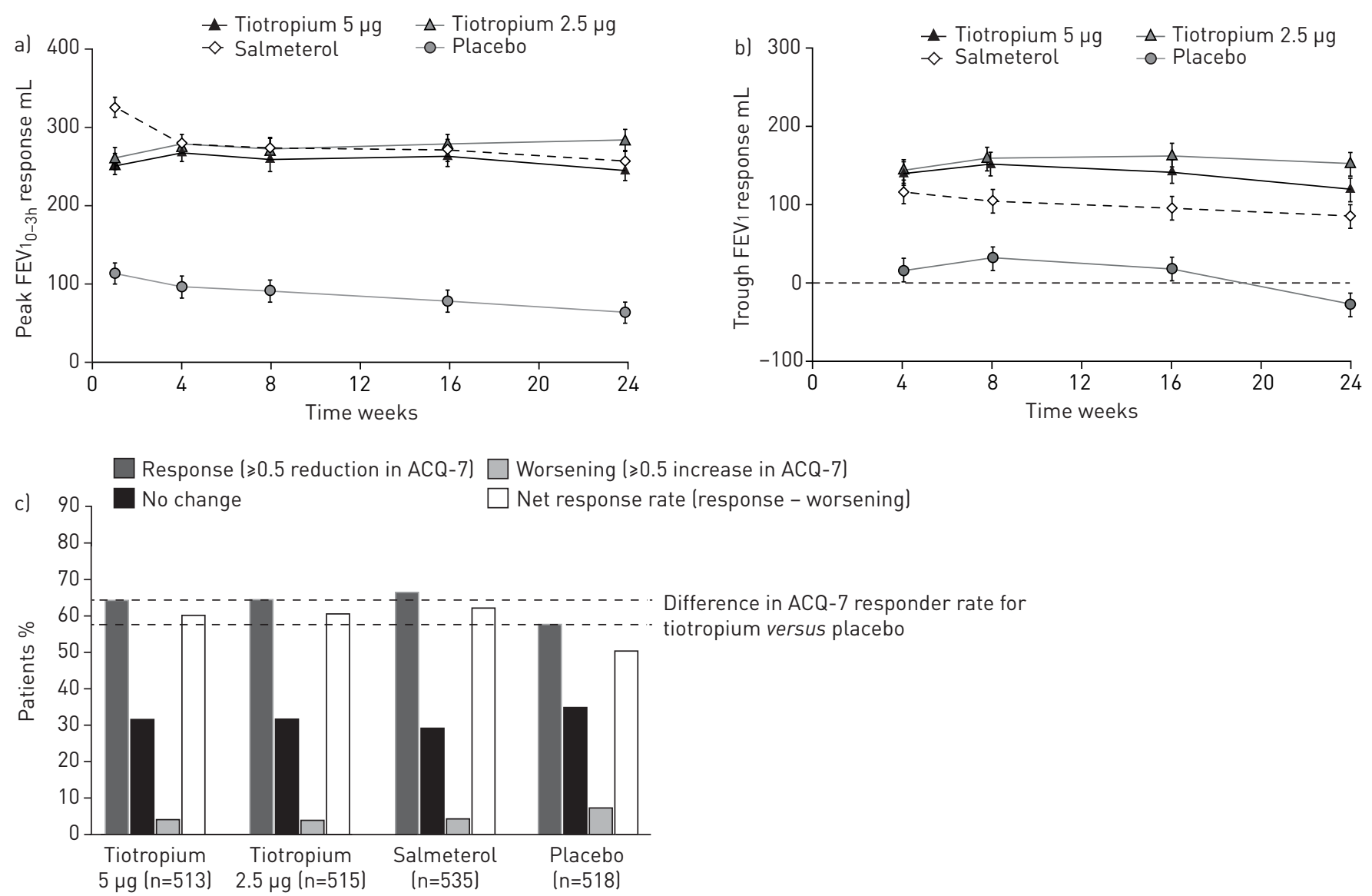

FIGURE 2 a) Peak forced expiratory volume in $1 \mathrm{~s}$ within $3 \mathrm{~h}$ post-dosing (peak $F E V_{1_{0-3 h}}$ ) response following once-daily tiotropium Respimat add-on to medium-dose inhaled corticosteroids (ICS) in adults with moderate symptomatic asthma. Pooled data (NCT01172808 and NCT01172821); all $\mathrm{p}<0.0001$ versus placebo. Full analysis set. b) Trough forced expiratory volume in $1 \mathrm{~s}$ (FEV 1 ) response following once-daily tiotropium Respimat add-on to medium-dose ICS in adults with moderate symptomatic asthma. Pooled data (NCT01172808 and NCT01172821); all p<0.0001 versus placebo except salmeterol at week 16 (p=0.0002). Full analysis set. Data are presented as mean \pm SE. c) Seven-question Asthma Control Questionnaire (ACQ-7) responder rate following once-daily tiotropium Respimat add-on to medium-dose ICS in adults with moderate symptomatic asthma. Pooled data (NCT01172808 and NCT01172821). Adjusted mean \pm SD ACQ-7 score response versus placebo: $-0.12 \pm 0.04$ ( $p=0.0084$ ) with tiotropium $5 \mu \mathrm{g} ;-0.16 \pm 0.04$ ( $p=0.0002)$ with tiotropium $2.5 \mu \mathrm{g}$; and $-0.20 \pm 0.04(p<0.0001)$ with salmeterol. Full analysis set. Reproduced and modified from [59] with permission from the publisher.

asthma, to determine whether tiotropium add-on therapy may also help to address the current unmet need in paediatric asthma patients.

\section{Real-life evidence of tiotropium add-on therapy in asthma}

The current body of clinical trial evidence suggests that tiotropium provides an efficacious add-on to at least ICS maintenance therapy in patients with asthma, with balanced safety and tolerability compared with placebo. It is also important to determine the therapeutic effectiveness of new treatment options in real-life populations, settings and durations to complement clinical trial data. Although established standards for real-life studies are not yet available, the appropriateness and quality of the study design, analyses and reporting, and the discussion of results, are important considerations in the interpretation of data [62].

A retrospective study of data from a real-life UK asthma population of 2042 patients showed that the addition of tiotropium therapy, either $18 \mu \mathrm{g}$ via the Spiriva HandiHaler device (93\%) or $5 \mu \mathrm{g}$ via the Respimat Soft Mist inhaler (7\%), was associated with significant decreases in the incidence of exacerbations and antibiotic prescriptions for lower respiratory tract infections, and a significant increase in asthma control in the year following subscription. Findings showed that primary care physicians in the UK have been prescribing long-acting anticholinergics for the treatment of asthma since 2002, predominantly as an add-on therapy in older patients with poorly controlled asthma despite good treatment compliance, particularly in those who are current or former smokers [63]. Similarly, in a second retrospective study of real-life data from 64 patients with severe asthma in Turkey, tiotropium add-on to high-dose ICS plus LABA therapy was found to significantly improve the percentage of patients with 
uncontrolled asthma, the number of emergency department visits, the number of hospitalisations and lung function, in addition to significant decreases in ICS dose, oral corticosteroid use and antibiotics for upper respiratory tract disease [64]. Both studies were well designed, with results consistent with those from randomised clinical trials of tiotropium in asthma. Further real-life studies of longer duration, with larger patient numbers and across broader patient populations, will be beneficial to provide valuable data on the efficacy and safety of tiotropium in patients with asthma.

Cost-effectiveness is an important consideration in relation to incorporating new treatment options into practice and determining their relative place in therapeutic strategies. The first modelled analysis of the cost-effectiveness of tiotropium add-on therapy, from the perspective of the UK National Health Service, was performed by WiLLSON et al. [65] using data from the two trials in adult patients with severe asthma (NCT00772538 and NCT00776984); tiotropium Respimat was found to provide a cost-effective treatment option for patients with severe symptomatic asthma despite treatment with high-dose ICS plus LABA therapy. Further cost-effectiveness analyses across different age ranges and severities of asthma may help to determine the extent to which tiotropium add-on therapy provides an affordable treatment option to help address current unmet needs in asthma treatment.

\section{Summary and conclusions}

A significant proportion of patients with asthma do not achieve control despite treatment with ICS alone or in combination with a LABA. Studies of long-acting anticholinergic bronchodilators as controller medications in the treatment of asthma are currently ongoing, with published results from clinical trials of glycopyrrolate, umeclidinium and tiotropium in asthma. Further data are needed to provide more evidence on glycopyrrolate and umeclidinium as potential treatment options. Data are now available from a number of studies of tiotropium as an add-on to at least ICS maintenance therapy across severities of symptomatic asthma in both adult and paediatric patients.

Long-acting anticholinergics were not included in recommended asthma treatment guidelines until 2015; however, tiotropium Respimat has recently been incorporated into the GINA strategy as an alternative add-on treatment option at steps 4 and 5 in adult patients with a history of exacerbations [4]. The benefit/ risk ratio of ICS therapy has been shown to decrease at high ICS doses $[66,67]$ and the addition of tiotropium is therefore likely to provide an alternative to increasing the ICS dose at GINA step 4, and before introducing more complex and costly alternatives at GINA step 5, such as anti-IgE or bronchial thermoplasty. In patients with less severe disease, tiotropium may also offer an alternative add-on therapy in patients where LABAs are not well tolerated, pose a higher risk of adverse events or are ineffective [68].

Head-to-head studies may also be helpful in determining the comparative efficacy of tiotropium in relation to other add-on treatment options. Although it has been suggested that anticholinergics may provide the most benefit in older patients, in patients with allergic asthma or nocturnal asthma, or in smokers or obese patients who are corticosteroid-resistant, this will require further investigation [28, 69-73].

In conclusion, ongoing and further studies of tiotropium add-on therapy, particularly in children and adolescents, as well as publication of phase II and III studies of emerging therapeutic options such as glycopyrrolate and umeclidinium, will provide direction on the use of anticholinergics in the treatment of asthma. Additional real-life studies involving patients of different ages with a range of demographics, including differing ethnicities, concomitant diagnoses and concurrent smoking, would also help to improve individual patient management [74].

\section{Acknowledgements}

The authors take full responsibility for the scope, direction, content of and editorial decisions relating to the manuscript, were involved at all stages of development, and have approved the submitted manuscript. Stephen Peters (Wake Forest Baptist Medical Center, Winston-Salem, NC, USA), although not a contributing author to this paper, reviewed the sections of this manuscript which related to research that he had conducted [51,52]. Medical writing assistance, in the form of the preparation and revision of the manuscript, was supported financially by Boehringer Ingelheim and provided by Lianne Young (Complete HealthVizion) under the authors' conceptual direction and based on feedback from the authors.

\section{References}

1 World Health Organization. Asthma. Fact sheet No307. www.who.int/mediacentre/factsheets/fs307/en/index.html Date last updated: 2013. Date last accessed: August 6, 2015.

2 Masoli M, Fabian D, Holt S, et al. The global burden of asthma: executive summary of the GINA Dissemination Committee report. Allergy 2004; 59: 469-478.

3 Schmier JK, Manjunath R, Halpern MT, et al. The impact of inadequately controlled asthma in urban children on quality of life and productivity. Ann Allergy Asthma Immunol 2007; 98: 245-251.

4 Global Initiative for Asthma. Global Strategy for Asthma Management and Prevention. Updated 2015. www. ginasthma.org/local/uploads/files/GINA_Report_2015.pdf Date last updated: April, 2015. Date last accessed: August 6, 2015. 
5 Demoly P, Paggiaro P, Plaza V, et al. Prevalence of asthma control among adults in France, Germany, Italy, Spain and the UK. Eur Respir Rev 2009; 18: 105-112.

6 Partridge MR, Dal Negro RW, Olivieri D. Understanding patients with asthma and COPD: insights from a European study. Prim Care Respir J 2011; 20: 315-323.

7 Barnes PJ. New therapies for asthma: is there any progress? Trends Pharmacol Sci 2010; 31: 335-343.

8 Canonica GW, Baena-Cagnani CE, Blaiss MS, et al. Unmet needs in asthma: Global Asthma Physician and Patient (GAPP) Survey: global adult findings. Allergy 2007; 62: 668-674.

9 Bateman ED, Boushey HA, Bousquet J, et al. Can guideline-defined asthma control be achieved? The Gaining Optimal Asthma ControL study. Am J Respir Crit Care Med 2004; 170: 836-844.

10 Rabe KF, Adachi M, Lai CKW, et al. Worldwide severity and control of asthma in children and adults: the global Asthma Insights and Reality surveys. J Allergy Clin Immunol 2004; 114: 40-47.

11 FitzGerald JM, Boulet LP, McIvor RA, et al. Asthma control in Canada remains suboptimal: the Reality of Asthma Control (TRAC) study. Can Respir J 2006; 13: 253-259.

12 Liu AH, Gilsenan AW, Stanford RH, et al. Status of asthma control in pediatric primary care: results from the pediatric Asthma Control Characteristics and Prevalence Survey Study (ACCESS). J Pediatr 2010; 157: $276-281$.

13 Vos T, Flaxman AD, Naghavi M, et al. Years lived with disability (YLDs) for 1160 sequelae of 289 diseases and injuries 1990-2010: a systematic analysis for the Global Burden of Disease Study 2010. Lancet 2012; 380: $2163-2196$.

14 Wechsler ME. Getting control of uncontrolled asthma. Am J Med 2014; 127: 1049-1059.

15 Akinbami LJ, Moorman JE, Liu X. Asthma prevalence, health care use, and mortality: United States, 2005-2009. Natl Health Stat Report 2011; 32: 1-14.

16 Ivanova JI, Bergman R, Birnbaum HG, et al. Effect of asthma exacerbations on health care costs among asthmatic patients with moderate and severe persistent asthma. J Allergy Clin Immunol 2012; 129: 1229-1235.

17 Haughney J, Gruffydd-Jones K. Patient-centred outcomes in primary care management of COPD - what do the clinical trial data tell us? Prim Care Respir J 2004; 13: 185-197.

18 Miller MK, Lee JH, Miller DP, et al. Recent asthma exacerbations: a key predictor of future exacerbations. Respir Med 2007; 101: 481-489.

19 Dougherty RH, Fahy JV. Acute exacerbations of asthma: epidemiology, biology and the exacerbation-prone phenotype. Clin Exp Allergy 2009; 39: 193-202.

20 Menezes AMB, Montes de Oca M, Pérez-Padilla R, et al. Increased risk of exacerbation and hospitalization in subjects with an overlap phenotype: COPD-asthma. Chest 2014; 145: 297-304.

21 Hardin M, Silverman EK, Barr RG, et al. The clinical features of the overlap between COPD and asthma. Respir Res 2011; 12: 127.

22 Diette GB, Patino CM, Merriman B, et al. Patient factors that physicians use to assign asthma treatment. Arch Intern Med 2007; 167: 1360-1366.

23 Juniper EF, O'Byrne PM, Guyatt GH, et al. Development and validation of a questionnaire to measure asthma control. Eur Respir J 1999; 14: 902-907.

24 Juniper EF, Buist AS, Cox FM, et al. Validation of a standardized version of the Asthma Quality of Life Questionnaire. Chest 1999; 115: 1265-1270.

25 Sims EJ, Price D, Haughney J, et al. Current control and future risk in asthma management. Allergy Asthma Immunol Res 2011; 3: 217-225.

26 Belmonte KE. Cholinergic pathways in the lungs and anticholinergic therapy for chronic obstructive pulmonary disease. Proc Am Thorac Soc 2005; 2: 297-304.

27 Gosens R, Zaagsma J, Meurs H, et al. Muscarinic receptor signaling in the pathophysiology of asthma and COPD. Respir Res 2006; 7: 73.

28 Restrepo RD. Use of inhaled anticholinergic agents in obstructive airway disease. Respir Care 2007; 52: 833-851.

29 Park HW. The role of tiotropium in the management of asthma. Asia Pac Allergy 2012; 2: 109-114.

30 Wessler IK, Kirkpatrick CJ. The non-neuronal cholinergic system: an emerging drug target in the airways. Pulm Pharmacol Ther 2001; 14: 423-434.

31 Bateman ED, Rennard S, Barnes PJ, et al. Alternative mechanisms for tiotropium. Pulm Pharmacol Ther 2009; 22: 533-542.

32 Gosens R, Zaagsma J, Grootte Bromhaar M, et al. Acetylcholine: a novel regulator of airway smooth muscle remodelling? Eur J Pharmacol 2004; 500: 193-201.

33 Westby MJ, Benson MK, Gibson PG. Anticholinergic agents for chronic asthma in adults. Cochrane Database Syst Rev 2004; 3: CD003269.

34 Price D, Fromer L, Kaplan A, et al. Is there a rationale and role for long-acting anticholinergic bronchodilators in asthma? NPJ Prim Care Respir Med 2014; 24: 14023.

35 Novelli F, Malagrinò L, Dente FL, et al. Efficacy of anticholinergic drugs in asthma. Expert Rev Respir Med 2012; 6: 309-319.

36 Rodrigo G, Rodrigo C, Burschtin O. A meta-analysis of the effects of ipratropium bromide in adults with acute asthma. Am J Med 1999; 107: 363-370.

37 Rodrigo GJ, Rodrigo C. First-line therapy for adult patients with acute asthma receiving a multiple-dose protocol of ipratropium bromide plus albuterol in the emergency department. Am J Respir Crit Care Med 2000; 161: 1862-1868.

38 Rodrigo GJ, Rodrigo C. The role of anticholinergics in acute asthma treatment: an evidence-based evaluation. Chest 2002; 121: 1977-1987.

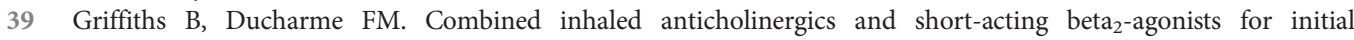
treatment of acute asthma in children. Cochrane Database Syst Rev 2013; 8: CD000060.

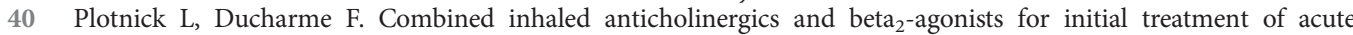
asthma in children. Cochrane Database Syst Rev 2000; 3: CD000060.

41 Rodrigo GJ, Castro-Rodriguez JA. Anticholinergics in the treatment of children and adults with acute asthma: a systematic review with meta-analysis. Thorax 2005; 60: 740-746.

42 Hansel TT, Neighbour H, Erin EM, et al. Glycopyrrolate causes prolonged bronchoprotection and bronchodilatation in patients with asthma. Chest 2005; 128: 1974-1979.

43 Lee LA, Briggs A, Edwards LD, et al. A randomized, three-period crossover study of umeclidinium as monotherapy in adult patients with asthma. Respir Med 2015; 109: 63-73. 
44 Lee LA, Yang S, Kerwin E, et al. The effect of fluticasone furoate/umeclidinium in adult patients with asthma: a randomized, dose-ranging study. Respir Med 2015; 109: 54-62.

45 O'Connor BJ, Towse LJ, Barnes PJ. Prolonged effect of tiotropium bromide on methacholine-induced bronchoconstriction in asthma. Am J Respir Crit Care Med 1996; 154: 876-880.

46 Terzano C, Petroianni A, Ricci A, et al. Early protective effects of tiotropium bromide in patients with airways hyperresponsiveness. Eur Rev Med Pharmacol Sci 2004; 8: 259-264.

47 Fardon T, Haggart K, Lee DKC, et al. A proof of concept study to evaluate stepping down the dose of fluticasone in combination with salmeterol and tiotropium in severe persistent asthma. Respir Med 2007; 101: 1218-1228.

48 Sposato B, Calabrese A, Barzan R, et al. Comparison of the protective effect amongst anticholinergic drugs on methacholine-induced bronchoconstriction in asthma. J Asthma 2008; 45: 397-401.

49 Iwamoto $\mathrm{H}$, Yokoyama A, Shiota N, et al. Tiotropium bromide is effective for severe asthma with noneosinophilic phenotype. Eur Respir J 2008; 31: 1379-1380.

50 Park HW, Yang MS, Park CS, et al. Additive role of tiotropium in severe asthmatics and Arg16Gly in ADRB2 as a potential marker to predict response. Allergy 2009; 64: 778-783.

51 Peters SP, Kunselman SJ, Icitovic N, et al. Tiotropium bromide step-up therapy for adults with uncontrolled asthma. N Engl J Med 2010; 363: 1715-1726.

52 Peters SP, Bleecker ER, Kunselman SJ, et al. Predictors of response to tiotropium versus salmeterol in asthmatic adults. J Allergy Clin Immunol 2013; 132: 1068-1074.

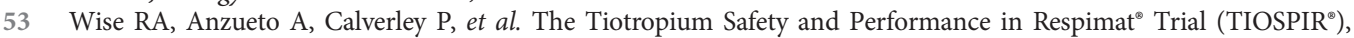
a large scale, randomized, controlled, parallel-group trial-design and rationale. Respir Res 2013; 14: 40.

54 Kerstjens HAM, Disse B, Schröder-Babo W, et al. Tiotropium improves lung function in patients with severe uncontrolled asthma: a randomized controlled trial. J Allergy Clin Immunol 2011; 128: 308-314.

55 Bateman ED, Kornmann O, Schmidt P, et al. Tiotropium is noninferior to salmeterol in maintaining improved lung function in B16-Arg/Arg patients with asthma. J Allergy Clin Immunol 2011; 128: 315-322.

56 Beeh KM, Moroni-Zentgraf $\mathrm{P}$, Ablinger $\mathrm{O}$, et al. Tiotropium Respimat ${ }^{\bullet}$ in asthma: a double-blind, randomised, dose-ranging study in adult patients with moderate asthma. Respir Res 2014; 15: 61.

57 Timmer W, Moroni-Zentgraf P, Cornelissen P, et al. Once-daily tiotropium Respimat ${ }^{\oplus} 5 \mu \mathrm{g}$ is an efficacious 24-hour bronchodilator in adults with symptomatic asthma. Respir Med 2015; 109: 329-338.

58 Kerstjens HAM, Engel M, Dahl R, et al. Tiotropium in asthma poorly controlled with standard combination therapy. N Engl J Med 2012; 367: 1198-1207.

59 Kerstjens HAM, Casale TB, Bleecker ER, et al. Tiotropium or salmeterol as add-on therapy to inhaled corticosteroids for patients with moderate symptomatic asthma: two replicate, double-blind, placebo-controlled, parallel-group, active-comparator, randomised trials. Lancet Respir Med 2015; 3: 367-376.

60 Vogelberg C, Engel M, Moroni-Zentgraf P, et al. Tiotropium in asthmatic adolescents symptomatic despite inhaled corticosteroids: a randomised dose-ranging study. Respir Med 2014; 108: 1268-1276.

61 Vogelberg C, Moroni-Zentgraf P, Leonaviciute-Klimantaviciene M, et al. A randomised dose-ranging study of tiotropium Respimat ${ }^{\circ}$ in children with symptomatic asthma despite inhaled corticosteroids. Respir Res 2015; 16: 20.

62 Roche N, Reddel H, Martin R, et al. Quality standards for real-world research. Focus on observational database studies of comparative effectiveness. Ann Am Thorac Soc 2014; 11: Suppl 2, S99-104.

63 Price D, Kaplan A, Jones R, et al. Long-acting muscarinic antagonist use in adults with asthma: real-life prescribing and outcomes of add-on therapy with tiotropium bromide. J Asthma Allergy 2015; 8: 1-13

64 Abadoglu O, Berk S. Tiotropium may improve asthma symptoms and lung function in asthmatic patients with irreversible airway obstruction: the real-life data. Clin Respir J 2014 [in press; DOI: 10.1111/crj.12230].

65 Willson J, Bateman ED, Pavord I, et al. Cost effectiveness of tiotropium in patients with asthma poorly controlled on inhaled glucocorticosteroids and long-acting $\beta$-agonists. Appl Health Econ Health Policy 2014; 12: 447-459.

66 Powell H, Gibson PG. Inhaled corticosteroid doses in asthma: an evidence-based approach. Med J Aust 2003; 178 : 223-225.

67 Szefler SJ, Martin RJ, King TS, et al. Significant variability in response to inhaled corticosteroids for persistent asthma. J Allergy Clin Immunol 2002; 109: 410-418.

68 Ortega VE, Hawkins GA, Moore WC, et al. Effect of rare variants in ADRB2 on risk of severe exacerbations and symptom control during longacting $\beta$ agonist treatment in a multiethnic asthma population: a genetic study. Lancet Respir Med 2014; 2: 204-213.

69 Ullah MI, Newman GB, Saunders KB. Influence of age on response to ipratropium and salbutamol in asthma. Thorax 1981; 36: 523-529.

70 Partridge MR, Saunders KB. Site of action of ipratropium bromide and clinical and physiological determinants of response in patients with asthma. Thorax 1981; 36: 530-533.

71 Bradding P, Green RH. Subclinical phenotypes of asthma. Curr Opin Allergy Clin Immunol 2010; 10: 54-59.

72 Lazarus SC, Chinchilli VM, Rollings NJ, et al. Smoking affects response to inhaled corticosteroids or leukotriene receptor antagonists in asthma. Am J Respir Crit Care Med 2007; 175: 783-790.

73 Chaudhuri R, Livingston E, McMahon AD, et al. Effects of smoking cessation on lung function and airway inflammation in smokers with asthma. Am J Respir Crit Care Med 2006; 174: 127-133.

74 Haughney J, Price D, Kaplan A, et al. Achieving asthma control in practice: understanding the reasons for poor control. Respir Med 2008; 102: 1681-1693. 